\title{
الصمود النفسي لاى طلبة الجامعة النازحين وغير النازحين
}

\section{م.د. اسيل صبار محمد}

جامعة الانبار / كلية التربية للعلوم الآسانية/قسم العلوم التربوية والنفسية معلد

\section{Mumnmom@yahoo.com}

ملخص

هدف البحث الحالي الى التعرف على دلالة الفروق في الصمود النفسي ما بـين طلبــة

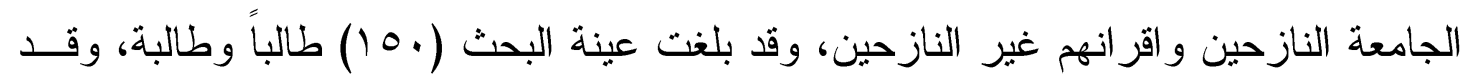
قامت الباحثة باعداد المقياس، وقد اسفرت نتائج البحث عن وجود فروق دالة احصائياً لصالح الطلبة غير النازحين.

مشكلة البحث: The Problem Of The Research

يعيش الفرد بصورة عامة وطلبة جامعة الانبار بصورة خاصة في هذا الوقت ظروفــا حياتية صعبة نتيجة احاطتهم من كل النواحي بالضغوطات المختلفة واخطر ها الارهاب الـذي لـي هدد كل بيت داخل المحافظة وخارجها مما شكل ضغطاً اقوى من الضغوط المعتاد عليها فــي حياتتا العادية فالضغوط المالية والاسرية و الجامعية وغيرها بالامكان التخفيف عن كاهل الفرد

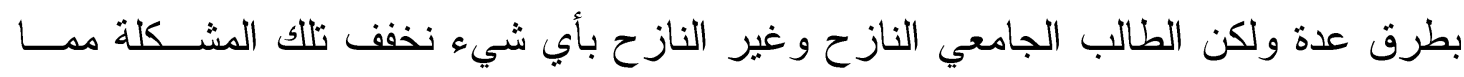
انعكس ذلك سالباً على استمر ارهم بالدر اسة وان استمروا ولكن بظروف قاسية جــــاً فغيـاب

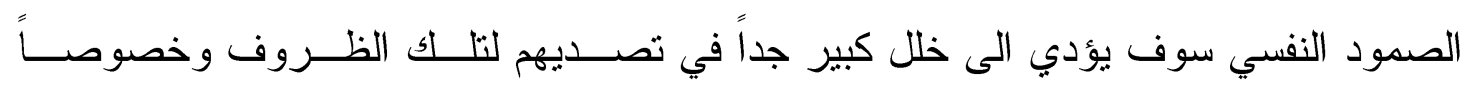
تعرضهم الى ازمة النزوح و التي تعد من الضغوط التي تحيط بالفرد فقدان البيوت و الممتلكات يؤدي الى الاحباط و العصبية ونزك تاثير ات نفسية سيئة على الصحة النفسـية و الجســمية. (Sherkety Reed, 1992,275)

و من خلال ذلك تحسست الباحثة بوجود المشكلة من خلال: ا ـ تحسس الباحثة بالمشكلة بوصفها احدى التذريسيات في الجامعة وكذلك قد عاشت حالة النزوح بشكل مباشر ولم تحتج الى تقديم استطلاع لأجل التأكد من تأصــل المشـــلة لكونها طرقت كل عائلة أنباريه. 
Y. انقطاع اعداد ليست بقليلة عن اداء الامتحانات داخل الجامعة بسبب محاصرة الارهاب

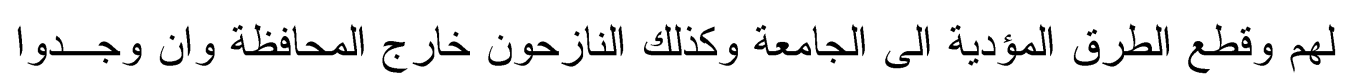
لديهم مكانا آمنا ولكن قد فقدوا الكثير داخل المحافظة مما انعكس هو الاخــر علـى ادائهم وكلتا الحالتين اثرت عليهم.

أهمية (لبحث: The Sign Finance Of Research ان للصمود النفسي الدور الفعال في زيادة قدرة تحمل الفرد للضغوطات بكل انواعهــا وغالباً ما تعد الضغوطات النفسية او عو امل الخطر المحيطة بالفرد لتكون تجــارب الاجهــاد

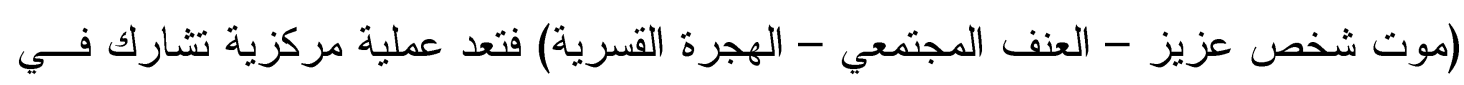
بناء القدرة على التكيف. وان هنالك بعض الجدل حول ما اذا كان الصمود سمة شخصية ام عملية دينامية (يشير الى قررة الفرد على التعلم في اية مرحلة من الحياة) ويفترض العديد من الباحثين ان الصمود من الممكن ان يكون سمة فطرية متأصلة يمتلكها كل شخص بدرجة ما ومن الممكن تعزيزها

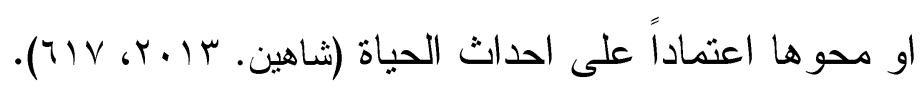
في حين اشـار البعض الى ان الصمود عملية نوعية دينامية وليس قدرة دائمة فــالافر اد الصامدون يظهر لديهم التجديد الذاتي في حين ان الافر اد الاقل صموداً يجدون انفسهم اكتــر ار هاقاً وسلباً امام مو اجهة الضغوطات. (Wind I, 2001,161) و اثار آخرون الى انه ليس صفة اخلاقية جيدة ولا صفة اخلاقية سيئة، بل انها مجـرد

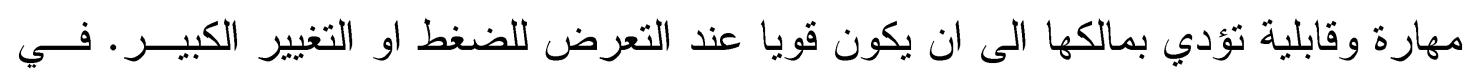

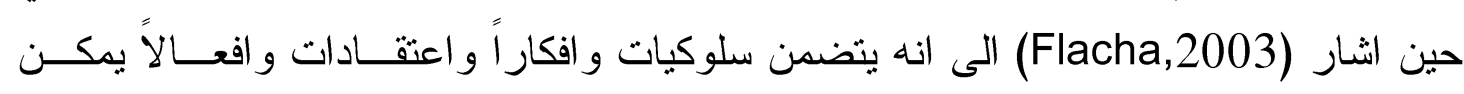
تعليمها وتنميتها لدى الفرد، فالفرد الصامد لديه القدرة على التكيف و التعامل مع ظروف الحياة (Flacha,2003:11)(المختلفة وفي ذلك الصدد فقد اشـار (Yorgason et al 2007) بانه العملية التي يتكيف الفـرد من خلالها مع المصاعب و الثدائد وينو افق معها(Yorgason et al 2007, 217)في حين يحـدد بأنه مقاومة الخبر ات القاسية و المو اقف الضاغطة و النهوض بفاعلية بعد هذه (Rutter 2007)

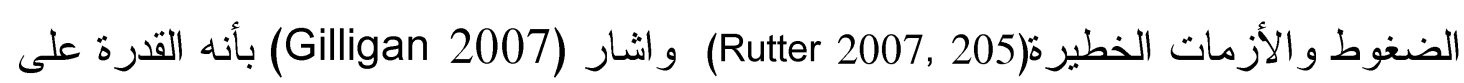

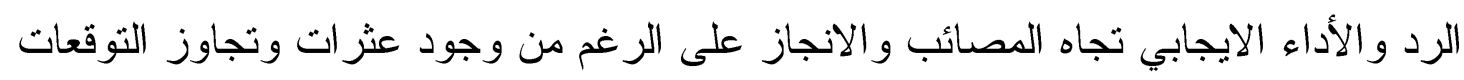
بشكل ملحوظ في ظل الظروف السلبية.(Machuca, 2010,p4) • 
ويستل على الصمود من خلال وجود خطر يهدد الفرد سواء كان هذا الخطر بيولوجيا او اجتماعيا او بيئيا و تعرض الفرد الى درجات متفاوتة من الاجهـاد واســتجابة للاجهـاد

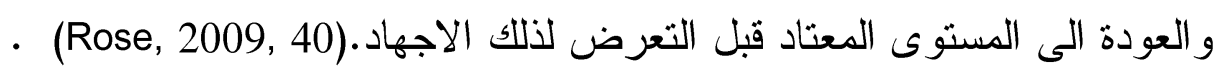
وثرى الباحثة انه لا يمكن لاي فرد ان يتحدث عن الصمود النفسي بعيداً عن التعرض للضغوطات و المحن و الصعاب. اذ يقاس ما لدى الفرد من صمود بقدر ما يستطيع ان يتخلــبـ او يو اجه تلك المحن بكل شجاعة وقوة. وكذلك فان الصمود النفسي يعمل كاليات الدفاع عن الفرد في وقت المحن ولكــن هـــهـ الاليات تختلف باختلاف الافر اد و البيئة المحيطة بهم وما تحمله من معاناة وصــعوبات فهـي تشهم بشكل ايجابي في جعل الصعوبات اقل تأثير على الفرد. وكذلك هنا تبرز الحاجة والاهمية للارشاد النفسي في مساعدة الطلبة الجـــامعيين علــى تحقيق قدر ولو بسيط من التكيف الفعال. فالفرد و الجماعة بحاجة الى الارشاد في مر احل نموهم المختلفة بسبب التغيرات الاسرية و الاجتماعية و التقدم العلمي و التكنولوجي، علاوة على القلق الذي نعيشه في هذا العصر .

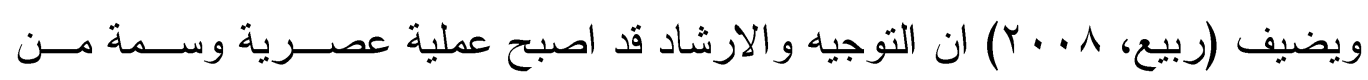
سمات النظم المعاصرة، و التي ير اد بها ومن خلالها مساعدة الطلبة على التكيف الســليم مـــع المحيط الجامعي و البيئة الاجتماعية التي يعيشون فيها(الداهري، ... ب).

و استتاداً لكل ما تقدم تبرز الاهمية النظرية و التطبيقية للبحث الحالي من خلاله ما يأتي: ا ـ الاهمية النظرية: وتتضح من خلال يعد البحث الحالي محاولة اولى على الصعيد المحلي في تتاول (الصمود النفسي) على حد علم الباحثة وخصوصاً شريحة النازحين. r. الاهمية التطبيقية: أ. توفير اداة لقياس الصمود النفسي ب. اثر اء معلومات المرشدين التربويين التي تسير العمليــة الارشــادية فــي الجامعــات العر اقية من اجل تقديم الخدمات للطلبة. 
هim Of The Research هدف البحث

يستهدف البحث الاتي الى تحقيق الهدف الاتي:

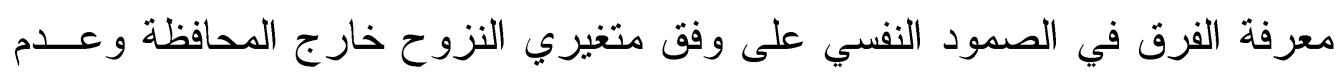

النزوح.

\section{حدود البحث: لتزوح Limitations Of Research}

يقتصر البحث الحالي على طلبة جامعة الانبار من الطلبة النازحين وغير النازحين في

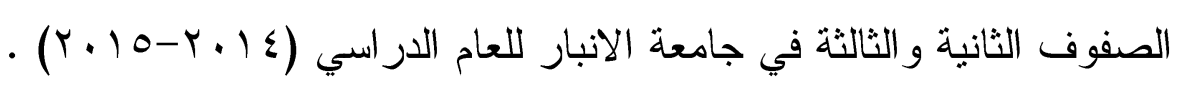

Definition Of The Terms تحديد المصطلحات

الصمود النفسي: Psychological Resilience

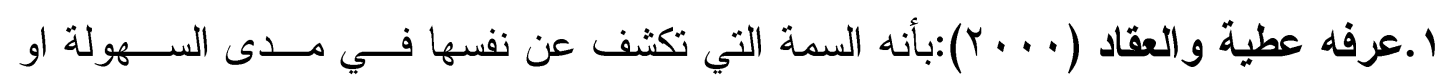

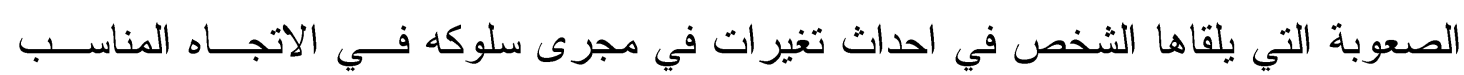

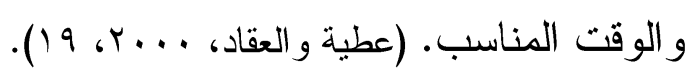

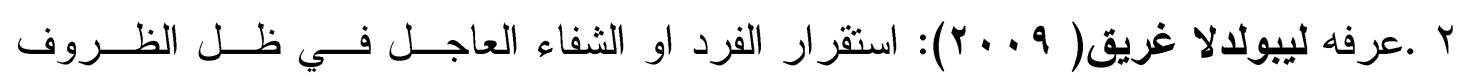

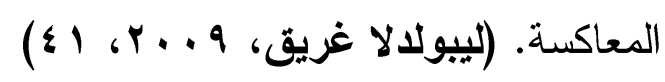

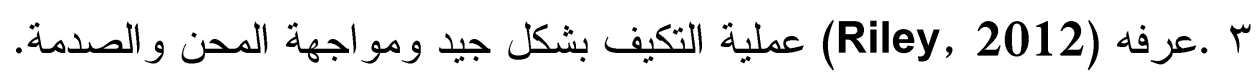
(Riley, 2012, 84)

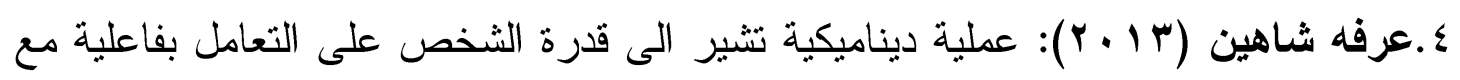

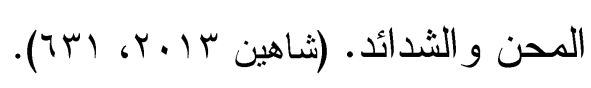

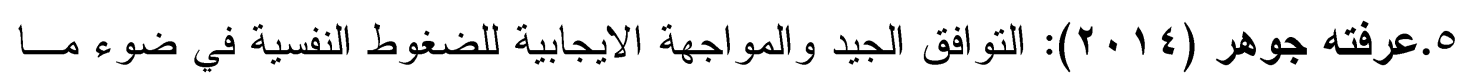
بملكه الفرد من كفاءة شخصية وقيم روحية ومساندة اجتماعبة

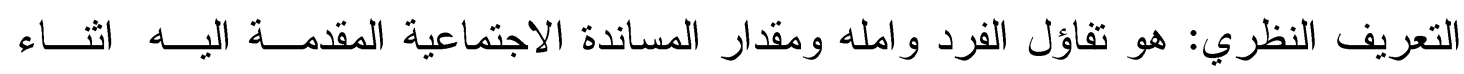
مو اجهته للمحن و الصعاب. اما التعريف الاجرائي: فهو الدرجة الكلية التي يحصل عليها المستجيب بعد اجابته على فقرات المقياس المستعمل في هذه الدراسة. 


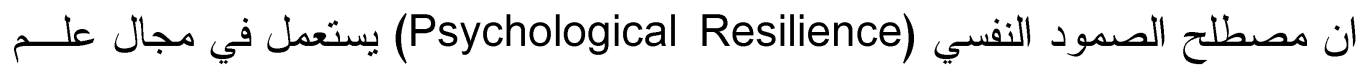
النفس الايجابي في الوقت الر اهن وعند تتاوله غالباً ما نجد ان معظم الناس يستعملونه بصورة

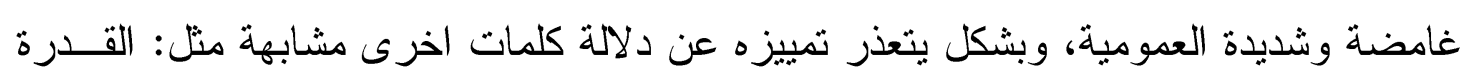

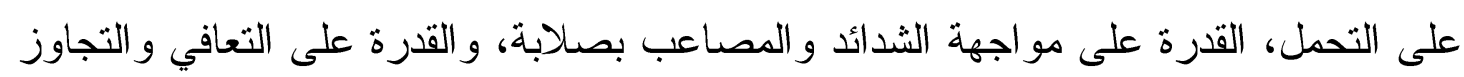
السريع للتأثير ات السلبية لأحداث الحياة.

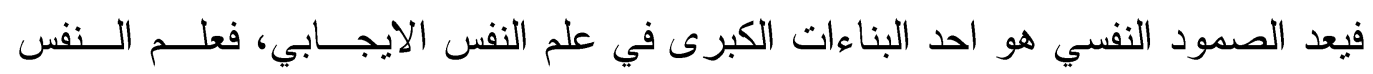

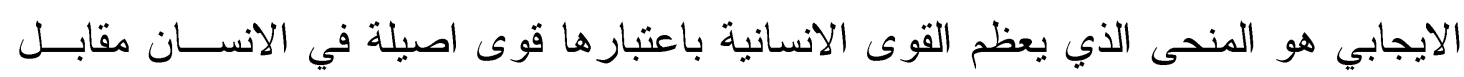

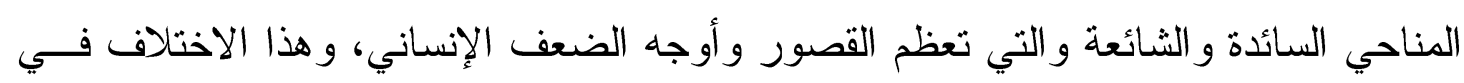
الرؤى لا يتعارض مع وحدة الهدف وهو تحقيق جودة الحياة.

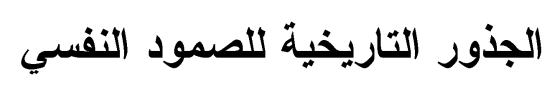

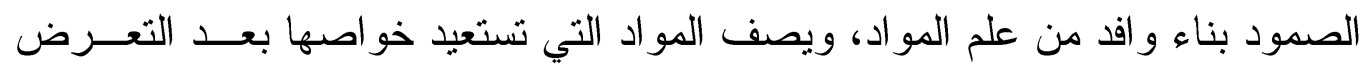
للطرق او التمدد او الانكماش و غيرها من المؤثرات الخارجية، وهو يحمل نفس المعنى الذئي

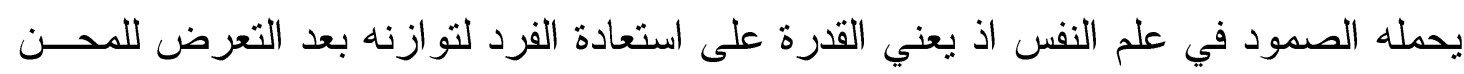

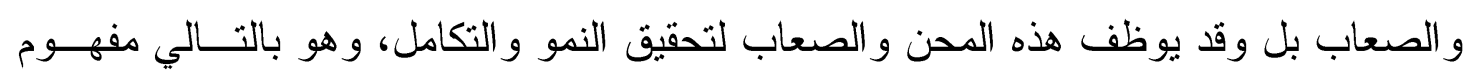

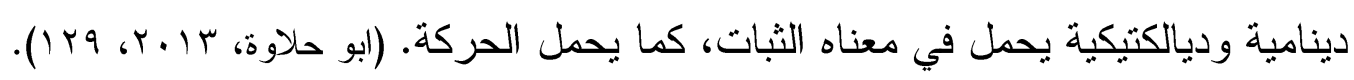

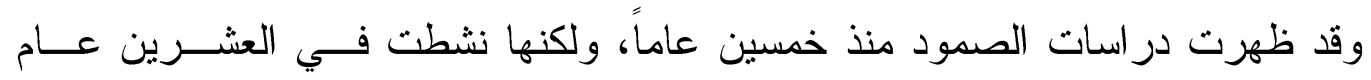

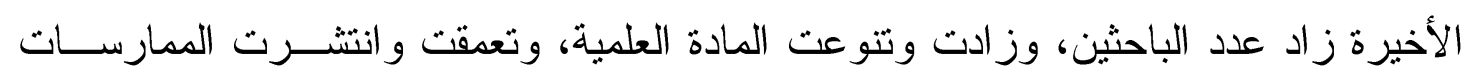

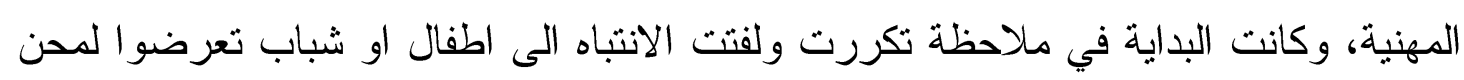

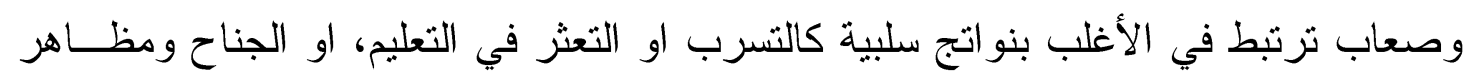

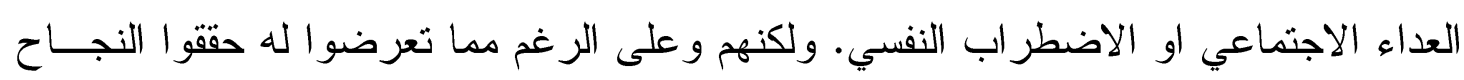
و التكامل على المستوى الشخصي و المهني و الاجتماعي. (الاعسر ، . (Y). 
مراحل دراسة الصمود النفسي

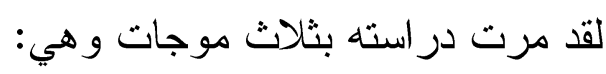

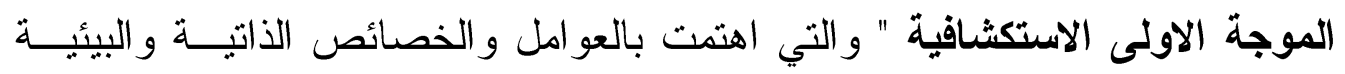

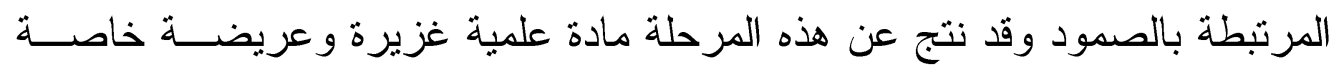

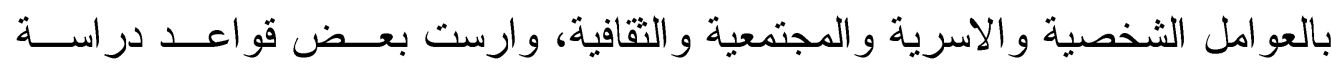

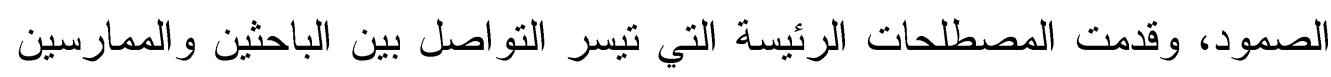

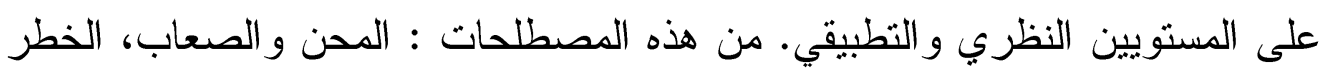

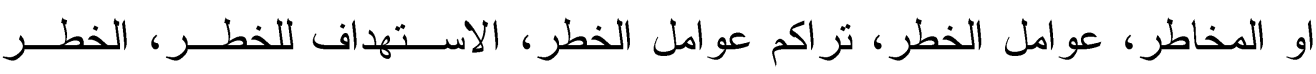

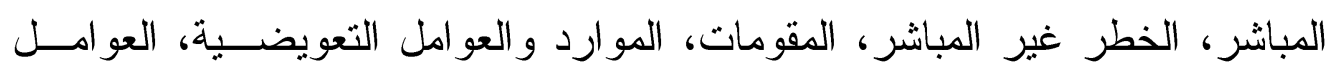

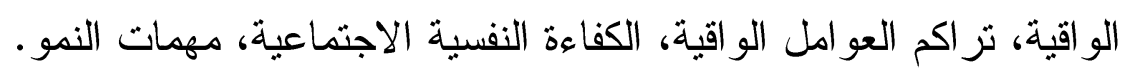

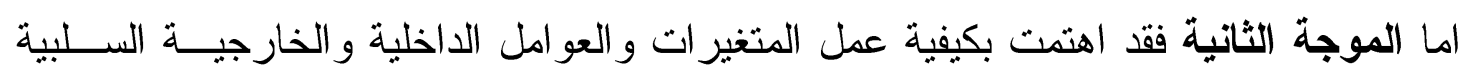

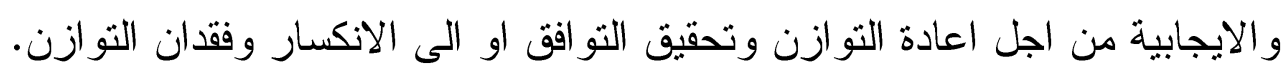

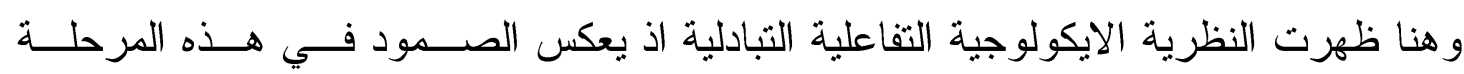

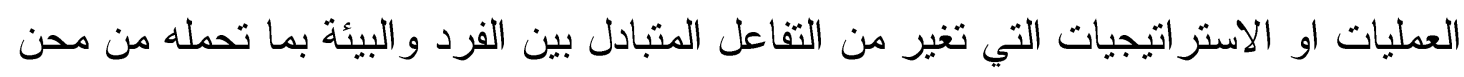

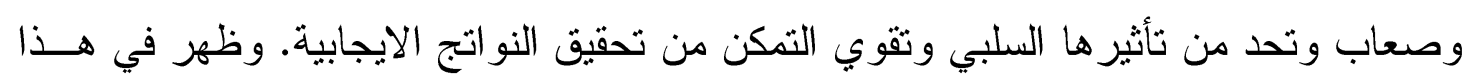

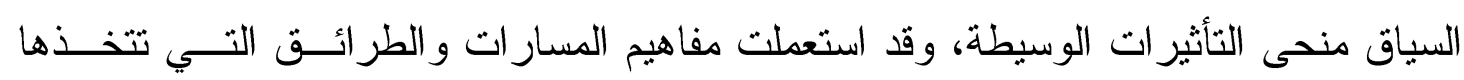

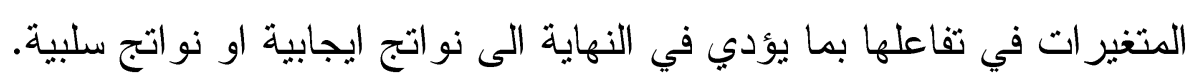

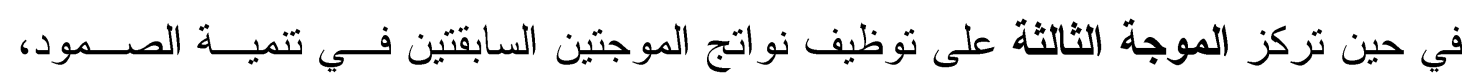

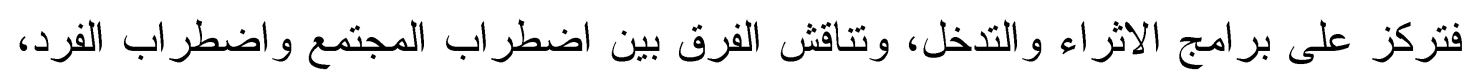

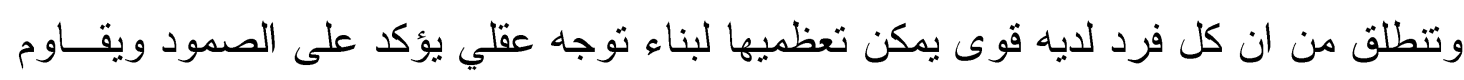

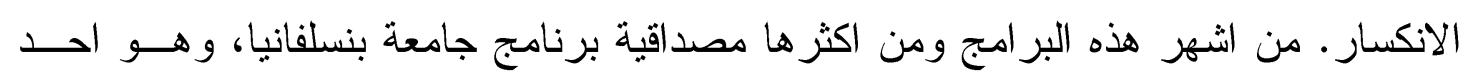

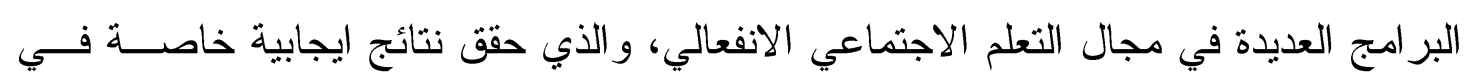

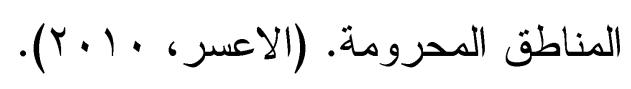
مكونات الصمود النفسي: لقد اختلفت الار اء حول مكونات الصمود النفسي فقد اثــار (Wicks , 2005) الــى عـدة

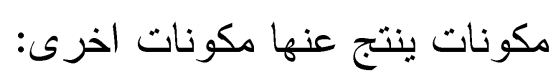


ا ـ. الرؤية الشخصية وتتضمن (الغرض و المعنى ، المبادئ و اهداف).

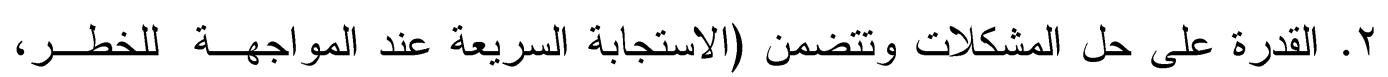
البحث عن المعلومات، والقيام بمخاطرة حاسمة).

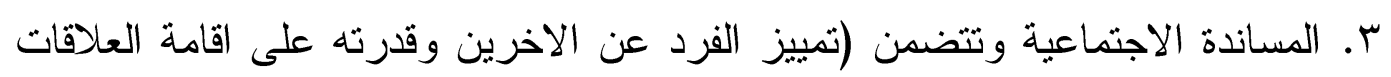

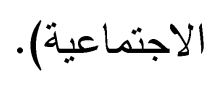

ع. ميكانيزمات الدفاع الانا وتتضمن (قدرة على فصل الانفعال، و اعادة البنية المعرفية)

(Wicks 2005, p. 15-16)

في حين انشار (Luthar \& Cicchetti, 2000) الى ان الصمود النفسي يشمل بعدين هما الكارثة و التكيف الايجابي (Luthar \& Cicchetti, 2000:858) في حين اشار (Koen, 2010) الى انه يتضمن (الأمل و التفاؤل و التحمل و الكفاءات

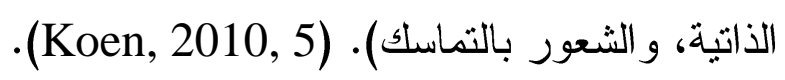

\section{سمات الافر اد الصامدين نفسياً:}

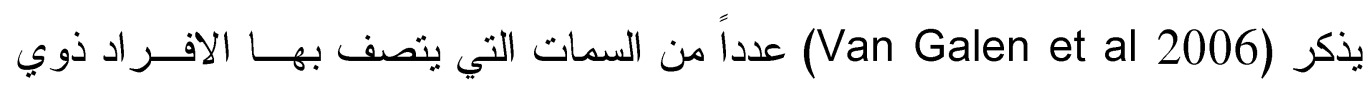

$$
\text { الصمود النفسي هي كالاتي: }
$$

r. اقامة علاقات جيدة مع الاخرين.

r. أمتلاك مهار ات تو اصلية معرفية جيدة.

ع. ارتفاع مستوى تقدير الذات وفاعلية الذات.

$$
\text { \. } 7 .
$$

^. امتلاك اساليب لمو اجهة الضغوط منو افقة مع طبيعة الفرد و الموقف.

$$
\text { 9. الانفعال الايجابي وروح الدعابة. }
$$

• ا. امتلاك المهار ات الفعالة في حل المشكلات.

$$
\text { الا الايمان بان الضغوط يمكن ان تزيد الفرد قوة. }
$$

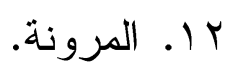

rا. تقبل المشاعر السلبية ومحاولة تخطي الخبرات السلبية. 


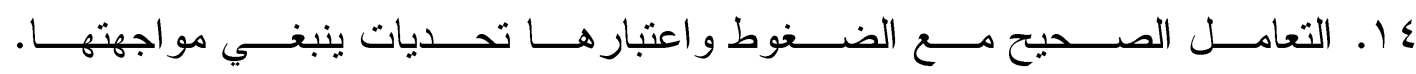

(Van Galen et al 2006, 6)

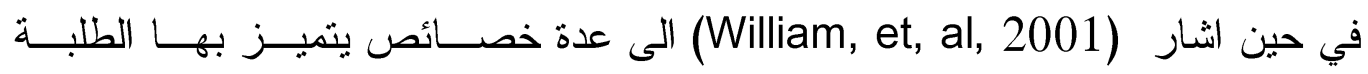
الصامدون نفسياً وهي:

ا ـ يتميزون بمستوى عال من دافعية الانجاز .

r. بتميزون بمستوى عال من السلامة النفسية. r. الديهم فاعلية للذات.

ع. لايهم القدرة على مواجهة الثدائد و الصعاب.

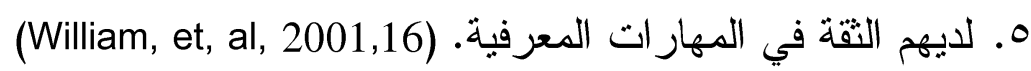

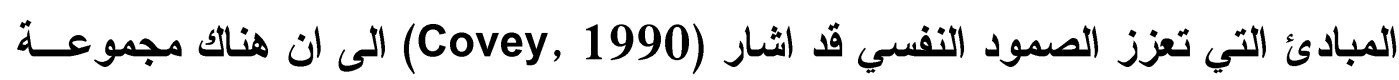

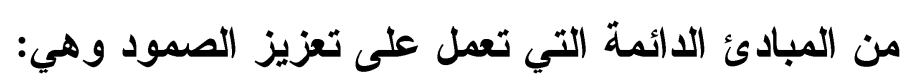

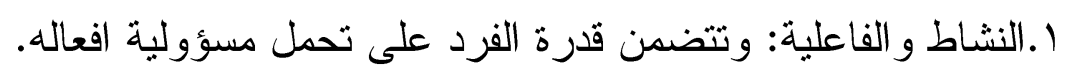

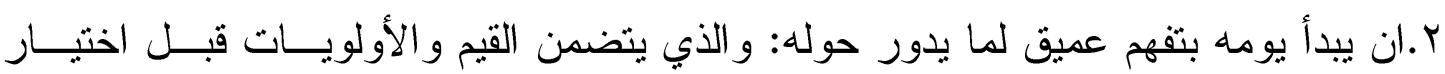

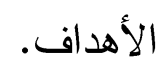

r.التعامل مع الأهم قبل المهم: من خلال تتظيم الوقت و إدارته وحسن استثماره.

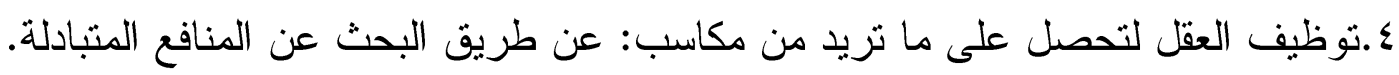

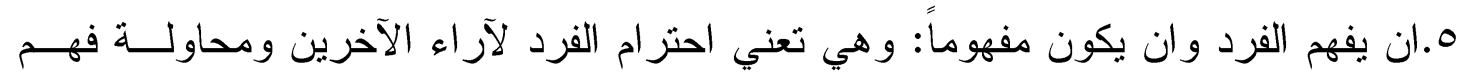
وجهة نظر هم.

4.التعاون: من خلال العمل بروح الفريق الذي تسوده قيم واحدة.(Wicks, 2005: 5).

\section{النظريات المفسرة للصمود النفسي:}

لقد اختلفت وجهات النظر المفسرة لذلك للمصطلح وقد تم ذكر بعض تلك وجهات النظر وهي:

اولا: نموذج ماستن وكوتسورث (Masten \& Coatsouth 1998):

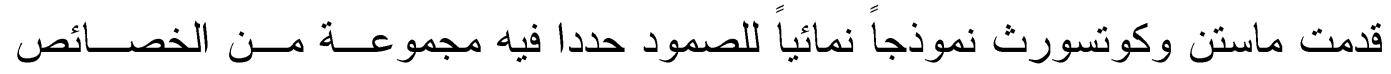

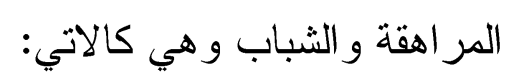

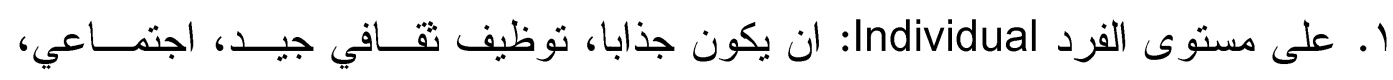
كفء، تقدير عالي للذات، مو هوب. 
r. على مستوى الاسرة Family: يتمتع بعلاقات اسرية جيدة ووطيدة، ويلقى الدعم مسن الأفر اد داخل العائلة.

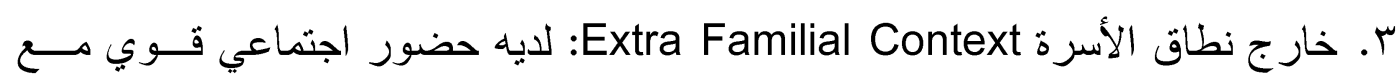

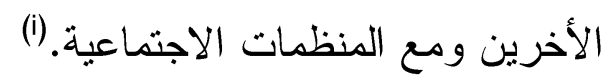

ثنانياً: نظرية العوامل الوقائية وعوامل الخطر: يرى (Luthar et al 2000)

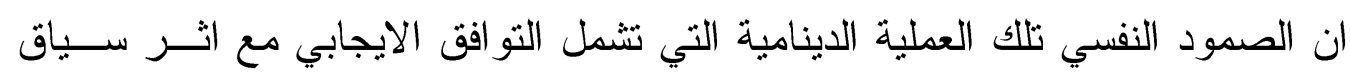
المصائب.

وقد ذكر (Thompson 2006) ان الصمود النفسي هو نوعية الأسـس التـي تتبنـى عملية التكيف الناجح و التحويل على الرغم من المصائب.

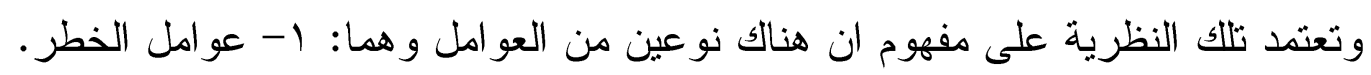

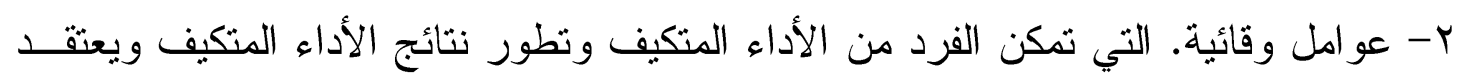

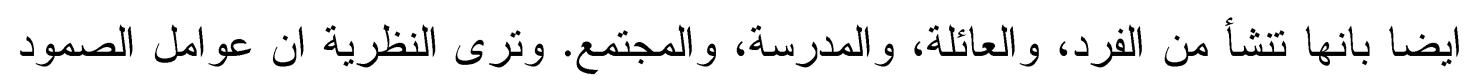
تتفاعل مع عوامل الخطر لتحسين او اقلال الأضرار السلبية والخطرة للأحداث.

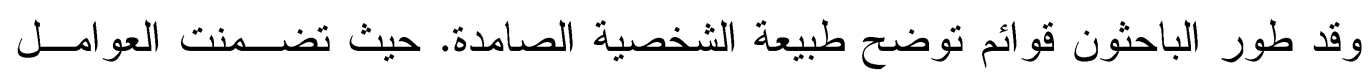

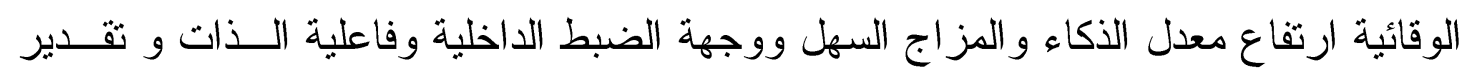
الذات ووجهة نظر ايجابية 1993 Werner.

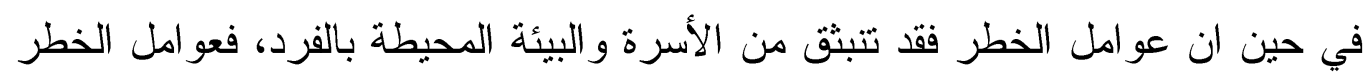

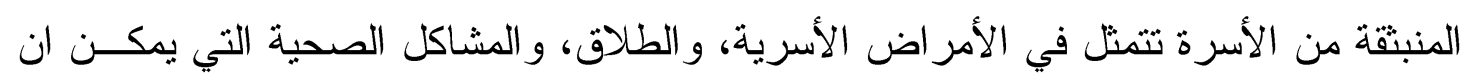

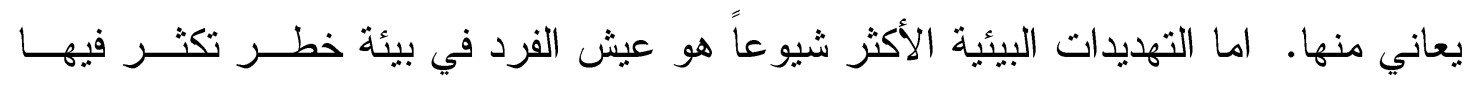
.(Vincent 2007) التهديدات

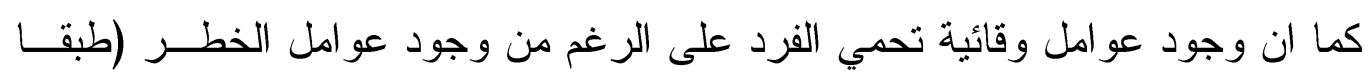
لنظرية الصمود لا عوامل الخطر او الوقاية) يتحدد بطبيعة التفاعل بين تلأك العو امل بنو عيها. (Weaver E Dale, 2009, P 116-117) ثالثاً: نظرية التوسع والبناء: لقد وصف (Fredrikson) النظرية في اي العواطف الايجابية التي تخــزن لبنــاء

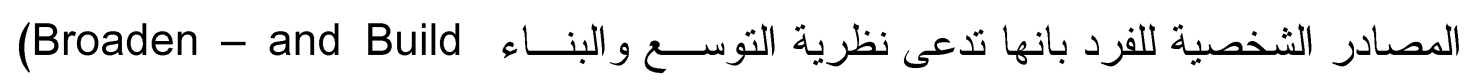
Theory) 
وطبقاً لهذه النظرية فالمصادر المخزونة (الامل - التفاؤل) يمكن ان تســب لاحقــاً

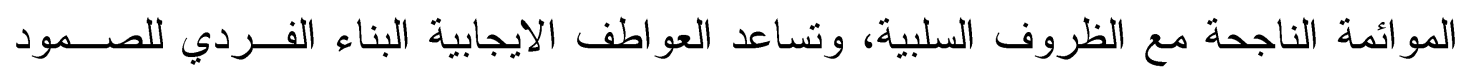
النفسي وتللك العو اطف الايجابية قد تثير فروق فردية في الصمود النفسي، كما يزيد الانفهـال

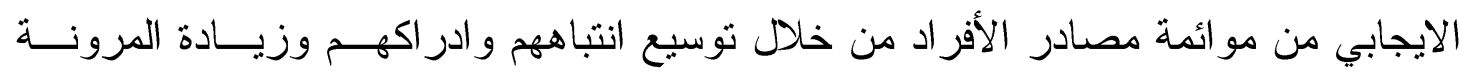
و التفكير الناقد. (Trapp, 2010, P 41-42)

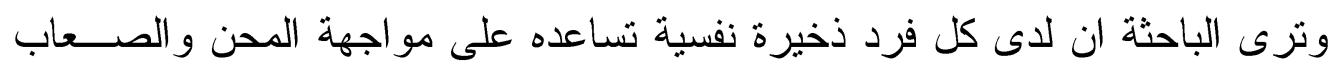

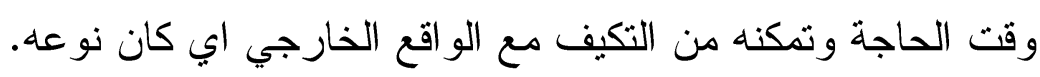




$$
\begin{aligned}
& \text { الاراسات السابقة: } \\
& \text { الاراسات العربية }
\end{aligned}
$$

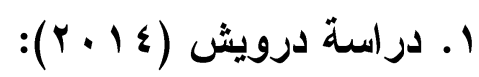

استهدفت هذه الدراسة الى التعرف على العلاقة ما بين الصمود النفسي و العو امل الخمسة درون

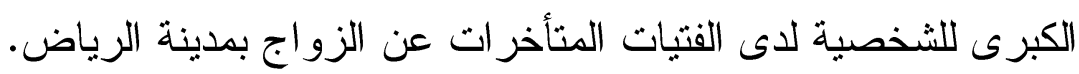

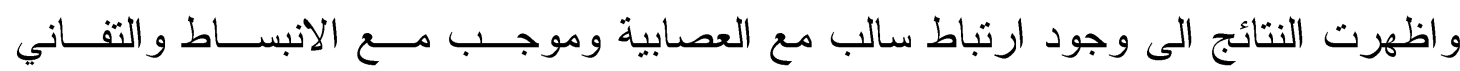

$$
\text { والدراسات الاجنبية: }
$$

الدراسة (Collins, 2010)

استهدفت هذه الدراسة الى بحث تأثير الامل في العلاقـــة بــين الخبــرات الحياتيـــة و الصمود و اسفرت النتائج عن وجود ارتباط ايجابي بين الصمود و الامل. (Collins, 2010)

r. براسة (Stratta et 2013)

استهدفت هذه الدر اسة التعرف على مستوى الصمود النفسي لدى عينة من الطلبة الذين

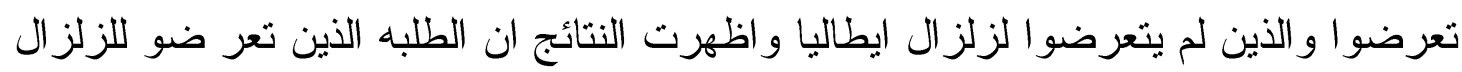
كانو ا اكثر صمودا من اقرانهم الذين لم يتعرضو للزلزال وكان هنالك فرقا دال لصالح الذكور

في الصمود النفسي(Stratta et 2013,327)

$$
\begin{aligned}
& \text { الاجر اعات: لقد تم اتباع الاجراعات الاتية: } \\
& \text { ا ـ مجتمع البحث: }
\end{aligned}
$$

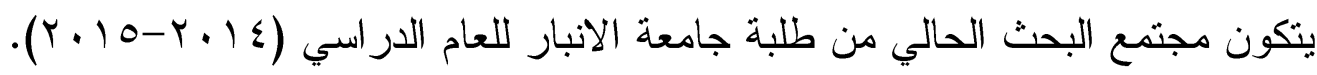

$$
\begin{aligned}
& \text { r. عينة البحث: }
\end{aligned}
$$

شملت عينة البحث الحالي طلبة الكليات الانسانية في جامعة الانبار من الطلبة النـازحين

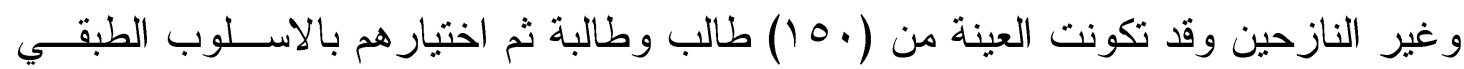


جملي: الآراب / العدر ع 11 10

جدول رقم (1)

توزيع افراد العينة

على اساس متميز النزوح (نازحون - غير نازحون)

\begin{tabular}{|c|c|}
\hline العدد & متغير النزوح \\
\hline$V \varepsilon$ & نازحون \\
\hline VY & غير نازحين \\
\hline 10. & لمجموع الكلي \\
\hline
\end{tabular}

ثالثاً: اداة البحث:

لقد قامت الباحثة بإعداد أداة البحث وهي كالاتي:

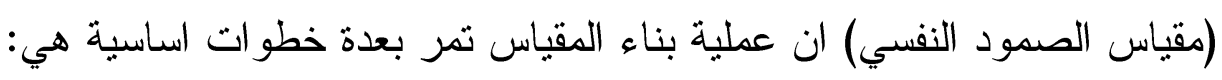
أ- التخطيط للمقياس وذللك بتحديد المجالات التي تغطيها فقر اته.

$$
\text { ب- - صياغة فقرات لكل مجال. }
$$

ج- تطبيق الفقرات على عينة ممثلة لمجتمع البحث.

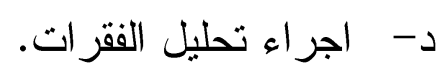

وقد تم اتباع الخطوات الآتية في عملية البناء وكما يأتي: أ. أ. أتخطيط للمقياس:

بتحديد المجالات التي تغطيها فقراته وبعد اطلاع الباحثــة علـى الادبيــات و الدراســات،

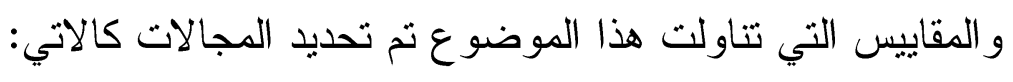

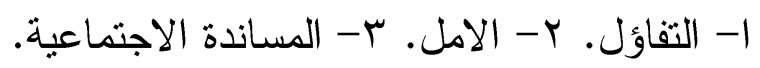

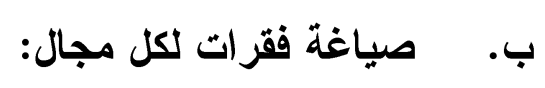

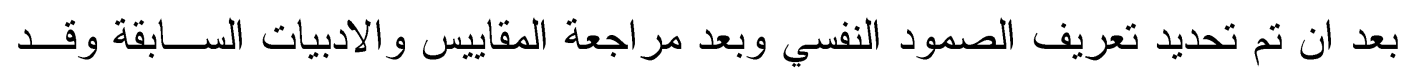
روعي في صياغة الفقرات ان تكون و اضحة وملائمة وان تكون قابلة لتفسير و احد.

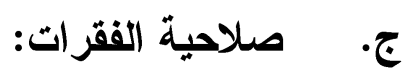


من اجل تعرف مدى صلاحية الفقرات (الصدق الظاهري قد عرضت بصورتها الاوليــة على مجموعة من المختصين في الارشاد النفسي و علم النفس لتحديد مدى صلاحية الفقرات

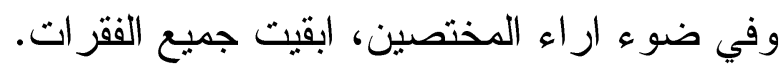

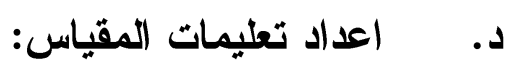

تعد تعليمات المقياس بمثابة دليلاً يسترشد به المستجيب لحظة استجابته لفقرات المقياس

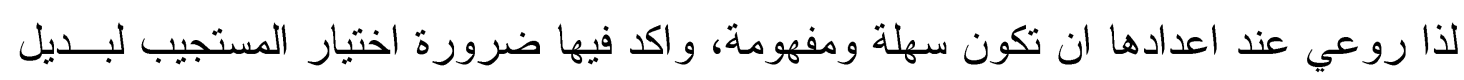

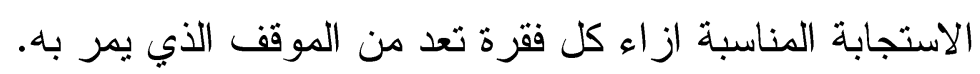

\section{هـ- تصحيح المقياس:}

تم اعتماد مقياس التدرج الخماسي از اء كل فقرة اذا اعطيت كل فقرة درجة تتز اوح مـــاس

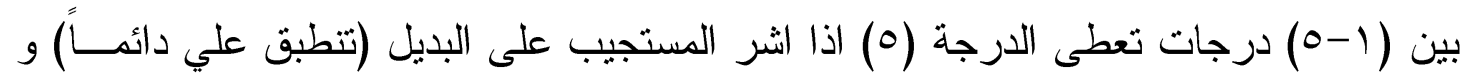

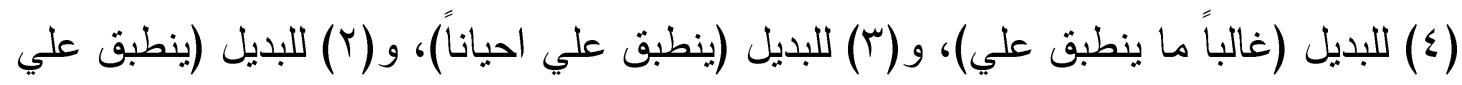

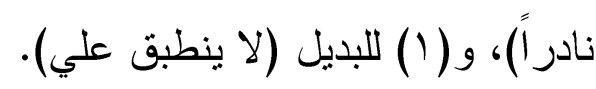

و-التحليل الاحصائي للفقرات :

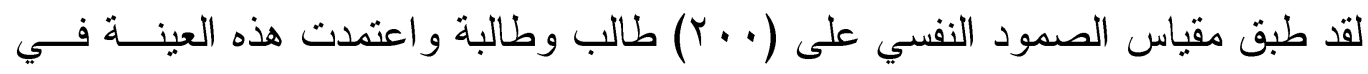

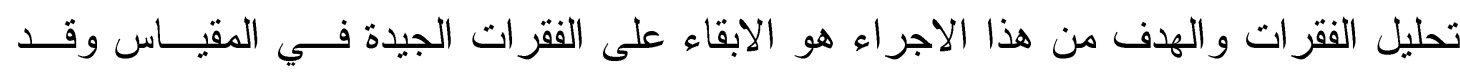

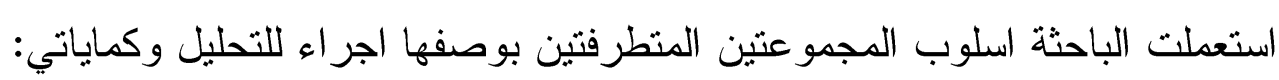
1- تحديد الدرجة الكلية لكل استمارة.

$$
\text { r- ترتيب الاستمارة من اعلى درجة الى ادنى درجة. }
$$

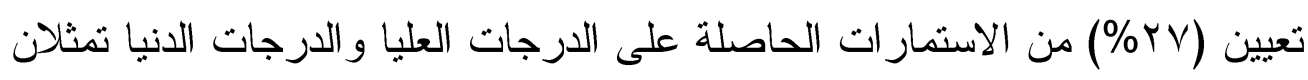
مجمو عتين بأكبر حجم و اقصى تمايز مدكن وبذللك اصبح مجموع افر اد المجوعة العليا (ع م) و الانبا (ع؛) و لاجل استخر اج القوة التميزية استعملت الباحثة الاختبار الثائي لعينتين مستقلتين لالالة الفروق بين المجموعة العليا و المجموعة الدنيا ، حيث كانت جميع القيم التائية المحسوبة اكبر من القيم التائية الجدولية وبدرجة حرية (106) وتبين ان جميع الفقر ات دالة احصائيا عند مسنوى دلالة (0,05 )، و الجدول ( ب ) يوضح ذللك. 


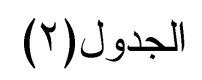

القوة التمييزية لفقرات مقياس الصمود النفسي بأسلوب المجموعتين المتطرفتين

\begin{tabular}{|c|c|c|c|c|c|c|}
\hline \multirow{2}{*}{ مستوى الدلالة } & \multirow{2}{*}{ القيمة } & \multicolumn{2}{|c|}{ المجموعة الانيا } & \multicolumn{2}{|c|}{ المجموعة العليا } & \multirow{2}{*}{ رقم } \\
\hline & & الانحر اف & الوسط الحسابي & الانحر اف & الحسابي & \\
\hline 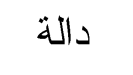 & 18.7 &.$r q$ & 1.1 &..$V V$ & Y.O. & 1 \\
\hline 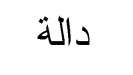 & 10.7 & .7. & 1.19 &. .70 & r.TY & r \\
\hline 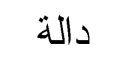 & $1 \varepsilon . V$ &..$\leqslant \varepsilon$ & 1.00 &. .77 & r.or & r ( - م \\
\hline 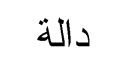 & 11 & . r人 & 1.19 &. $.7 V$ & r.Tr & $\varepsilon$ \\
\hline دالة ل & 17 &. .01 & س. &. .79 & r.Vq & 0 \\
\hline 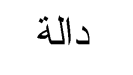 & 11.9 &. .71 & $1 . Y \wedge$ &. $.7 V$ & r.Tr & 7 \\
\hline 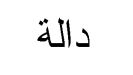 & IY.V &.$v V$ & 1.0 & . & r.Tr & v \\
\hline 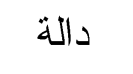 & r. &. .79 & $1 . \varepsilon$ &.$v 1$ & $r .79$ & $\wedge$ \\
\hline دالة ل & Ir.A &.$V Y$ & $1.0 r$ & .00 & r. . & 9 \\
\hline دالة ل & IY.A &..$\leqslant \varepsilon$ & 1.10 &..$V \wedge$ & r.r. & 1. \\
\hline 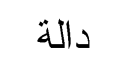 & 9.5 &..$r \varepsilon$ & $1 . .7$ &..$v r$ & $1 . \wedge r$ & 11 \\
\hline 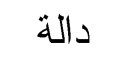 & r... & سب. & 1.14 &..$V Y$ & Y.1T & ir \\
\hline 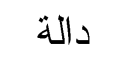 & $\mid r .1$ &. .77 & $1 . r V$ &. $.7 V$ & Y.EV & M \\
\hline د الة & 1.70 & .79 & Y.II &.$- \leqslant 0$ & Y.AI & $1 \leq$ \\
\hline دالة & דr.r & $.0 \mathrm{~V}$ & Y.TA & سب. . & $r . \wedge q$ & 10 \\
\hline
\end{tabular}




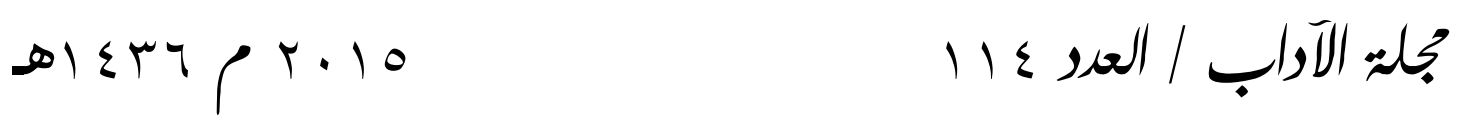

\begin{tabular}{|c|c|c|c|c|c|c|}
\hline دالة & $1 \cdot .1$ &..$\lambda r$ & $1.1 \mathrm{~V}$ &..$\wedge V$ & r.11 & 17 \\
\hline دالة & $r .90$ & . . & q & צחץ.. & Y.E^ & IV \\
\hline دالة & $V .71$ &.$v r$ & $r . \Sigma Y$ &.$r O V$ & $r .90$ & 11 \\
\hline دالة & r.YI & .04 & r.00 & .7 & $r . \wedge l$ & 19 \\
\hline دالة & $\varepsilon .01$ &.$v V$ & 1.79 & . vo & 4.11 & $r$. \\
\hline دالة & r. &..$v \varepsilon$ & Y.o. & .0 & r.VA & rI \\
\hline دالة & r.qu &..$V^{\prime}$ & $1 . \wedge \wedge$ & .10 & Y.YV & KY \\
\hline دالة & 11.11 &. .11 & r.11 &. .01 & r.VV & rr \\
\hline د دالة & r. &..$V V$ & rז.Y & .997 & r.0T & $r \varepsilon$ \\
\hline دالة & $0 . Y_{1}$ &.$\Delta 4$ & r.10 &. .77 & r.TV & ro \\
\hline دالة & 11.9 &.$V 0$ & I.A &..$\leqslant 1$ & r.VA & $r y$ \\
\hline دالة & $\varepsilon . \cdot r$ &.$\wedge$ & r.TE &. .71 & Y.VV & $r V$ \\
\hline دالة & 7.91 &. .19 & $1 . V$. &.$\Delta \mu$ & r.or & rA \\
\hline دالة & $r . . r$ & .07 & $1 . r Y$ &. .09 & مب. & $r q$ \\
\hline دالة & $V . .0$ &. .81 & r.IV &..$\leqslant 0$ & r.VE & r. \\
\hline دالة & 11.9 &. Vo & $1 . \wedge r$ &..$\leqslant 1$ & Y.VV & I \\
\hline دالة & r.7^ &..$\wedge \wedge$ & 1.17 &.$v 9$ & r. & rr \\
\hline دالة & Y.M & .79 & $1 . V$. & . VA & סr.r & سr \\
\hline دالة & r.人o &. $.7 V$ & r.TE & r & r.AT & r \\
\hline دالة & 7.10 &.$v Y$ & $1.9 \varepsilon$ & . . & r. r. & o \\
\hline دالة & $\varepsilon . \leqslant 0$ &. .71 & $1 . Y \wedge$ &. .VA & r. TA & דr \\
\hline دالة & T.M & .79 & $1 . V$. &..$V \wedge$ & סr.r & rv \\
\hline
\end{tabular}


ججلت الآراب / العدو ع 11

\begin{tabular}{|c|c|c|c|c|c|c|}
\hline دالة & Y.AO & .77 & 1.70 &..$\leqslant Y$ & Y.AY & r \\
\hline دالة & $\varepsilon . V Y$ & $.0 \leqslant$ & 1.99 & .74 & Y.TA & rq \\
\hline دالة & $\varepsilon . Y \wedge$ & $\cdot A \cdot r$ & $1 . V V$ &.$v$. & T. & $\varepsilon$. \\
\hline دالة & r.9r & .99 & 1.90 &..$\wedge V$ & ס T.T & \&) \\
\hline دالة & $r .09$ &.$\wedge r$ & $1 . \cdot 1$ & .10 & Y. $\varepsilon \varepsilon$ & $\varepsilon r$ \\
\hline دالة & r. $\leqslant q$ &. .91 & $1 . V V$ &..$\wedge 7$ & Y.OY & س \\
\hline دالة & $1 . .7$ &.$v$. & $1 . \wedge V$ & $\cdot . \leqslant \varepsilon$ & Y.VY & $\varepsilon \varepsilon$ \\
\hline دالة & $\varepsilon . \wedge V$ &. .71 & $1 . V 7$ &.$\wedge$. & Y.Ao & $\varepsilon 0$ \\
\hline دالة & $V .9 V$ &.$\wedge$ & $1.9 \leq$ & .00 & Y. 79 & $\varepsilon 7$ \\
\hline دالة & r.^ᄉ &. $.7 V$ & $1.7 \varepsilon$ &.. Y人 & $r .9 r$ & $\varepsilon V$ \\
\hline دالة & $r . \leqslant r$ &..$\wedge 1$ & $1 . V V$ &. .91 & r.11 & $\varepsilon \wedge$ \\
\hline دالة & r. & •.ر & 1.79 &. .81 & 1.91 & $\leqslant 9$ \\
\hline دالة & $\varepsilon . .1$ & •. & 1.17 & .10 & Y. YV & 0 . \\
\hline دالة & rוT.r &. .11 & r.Tr &..$\leqslant 1$ & $r . \wedge V$ & 01 \\
\hline دالة & $q . r \cdot v$ & 1.1 .1 & r. $\varepsilon \cdot V$ & .9 .0 & r. & or \\
\hline دالة & $r . q \mu q$ & $1 . .1 \leq$ & $r . r \leq 1$ & 1.1 .1 & r.01 & or \\
\hline دالة & $7.07 \varepsilon$ & M & Y.M & 1.11 & r.10 & 0\{ \\
\hline دالة & $0 . \Sigma \Lambda \mu$ & 1.1 & $Y . . T$ &..$V 1$ & T. & 00 \\
\hline
\end{tabular}




\section{ز. مؤشرات صدق المقياس:}

1-الصدق:

يعد صدق المقياس من الخصائص الاساسية في بناء المقاييس و المقياس الـــي يثبـــــ صدقه هو المقياس الصالح لقياس السمة التي وضع من الجلها. وقد تحقق في المقياس الحالي نوعان من الصدق هما:

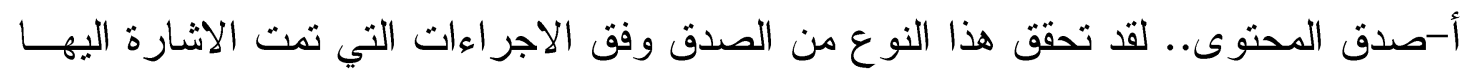
في خطوات البناء المشار اليها.

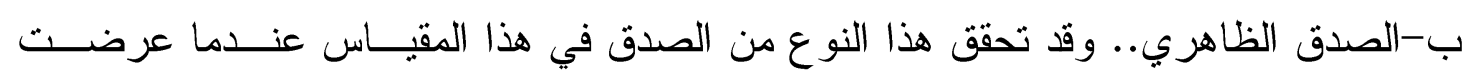

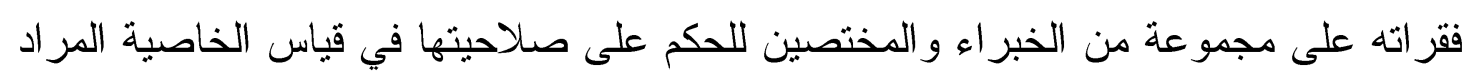
قياسها.

ج-صدق البناء.. ويقصد به مدى قدرة الاختبار و المقياس على كثف السمة لظاهرة ســلوكية

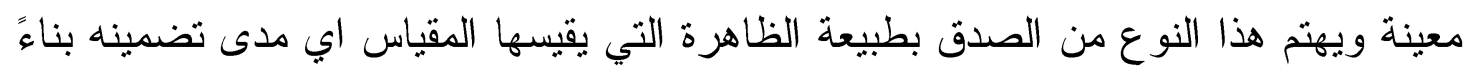

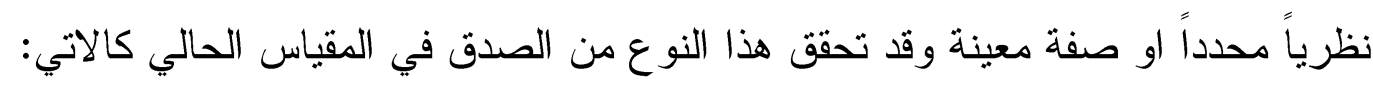
علاقة درجة الفقرة بالدرجة الكلية:

يعد معامل ارتباط درجة الفقرة بالدرجة الكلية مؤشراً لصدق البناء ولقد استعمل معامل

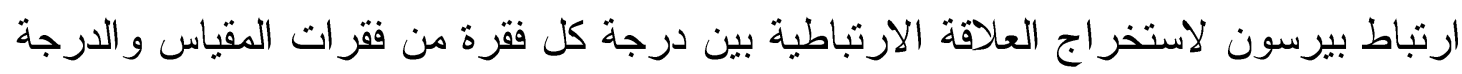

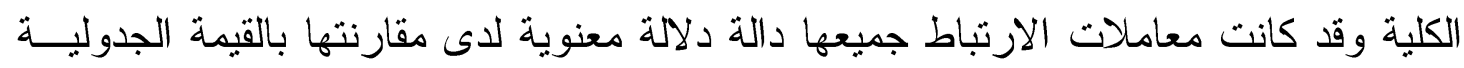

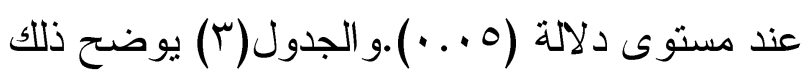


مجل: الآراب / العدر ع ال|

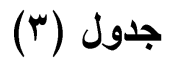

معامل إرتباط بيرسون لمعرفة معاملات ارتباط الفقرة بالدرجة الكلية

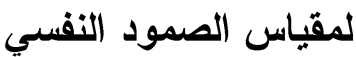

\begin{tabular}{|c|c|c|c|c|c|}
\hline معامل الارتباط & رقم الفقرة & معامل الارتباط & رقم الفقرة & معامل الارتباط & الفقرقة \\
\hline \multirow[t]{27}{*}{. $.9 \varepsilon$} & 00 & $\therefore .19$ & rA &. .99 & 1 \\
\hline & &. .90 & rq &. $.9 \mathrm{~V}$ & $r$ \\
\hline & & . . Ar & $r$. &. $.9 \varepsilon$ & $r$ \\
\hline & &. $.9 \varepsilon$ & 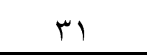 & .94 & $\varepsilon$ \\
\hline & &. .91 & rr &. $.9 \varepsilon$ & $\circ$ \\
\hline & &.$\wedge \wedge$ & r & $\therefore .9$. & 7 \\
\hline & &. .9 . & $r \varepsilon$ &. .91 & v \\
\hline & & $\therefore$... & ro & .99 & $\wedge$ \\
\hline & & $. .9 \leqslant$ & mi & $\therefore .9$. & 9 \\
\hline & &.$\Delta r$ & $r v$ & .94 & 1. \\
\hline & &.$\wedge \varepsilon$ & $r_{\Lambda}$ &. .97 & 11 \\
\hline & &. .10 & rq &. .97 & Ir \\
\hline & &. .9 . & $\varepsilon$. & .99 & $1 \pi$ \\
\hline & &. .90 & \&1 &. .97 & $1 \varepsilon$ \\
\hline & & ד & $\leqslant Y$ & ..11 & 10 \\
\hline & &. .94 & $\varepsilon r$ & $\therefore .19$ & 17 \\
\hline & & $\therefore .10$ & $\leq \varepsilon$ & $\therefore .10$ & IV \\
\hline & & $\therefore .90$ & $\leqslant 0$ & $\therefore \wedge \Lambda$ & 11 \\
\hline & & . & $\leq 4$ & . .Av & 19 \\
\hline & & .94 & $\leq V$ &. .19 & $r$. \\
\hline & & $\therefore .9$. & $\varepsilon \lambda$ & . & $r_{1}$ \\
\hline & & .147 & $\leqslant 9$ &. .91 & $r r$ \\
\hline & & $\therefore \wedge \Lambda$ & 0. & $\therefore .91$ & $r \mu$ \\
\hline & &. .19 & 01 &. $.9 \mathrm{~V}$ & $r \varepsilon$ \\
\hline & & . . & or &. .97 & ro \\
\hline & &.$\wedge 4$ & or & .97 & ry \\
\hline & &. .97 & $0 \leqslant$ &. .90 & TV \\
\hline
\end{tabular}


تحقق الثبات في هذا المقياس عن طريق اعادة الاختبار اذ قامــت الباحثــة باسـتعمال

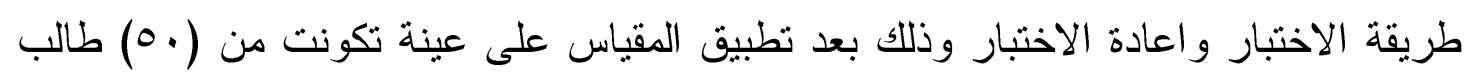

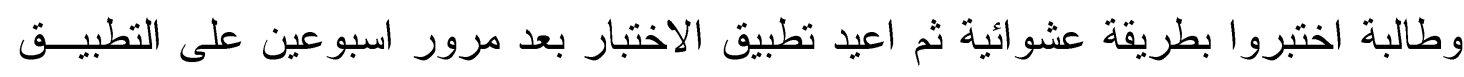

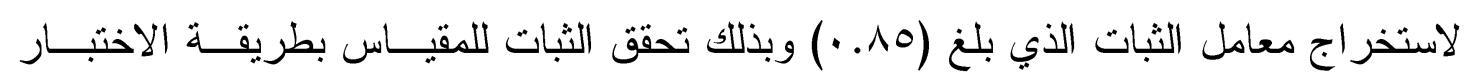

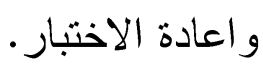

Statistical methods الوسائل الاحصائية 1. الاختبار التائي لعينتين مستقلتين.

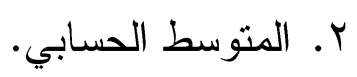

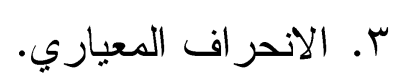
ع. معامل ارتباط بيرسون

النتائج: توصل البحث الحالي الى النتيجة الاتية:

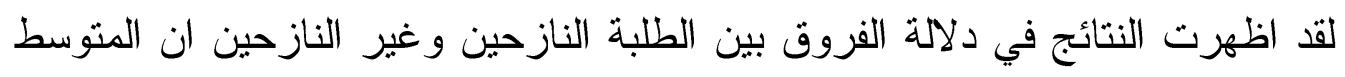

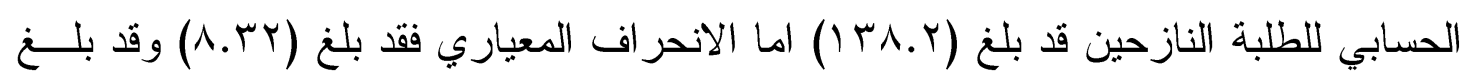

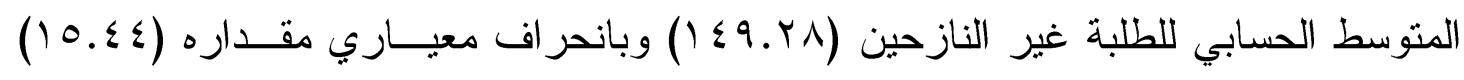

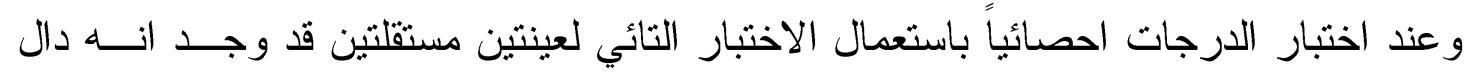

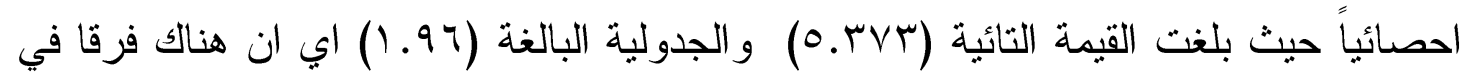

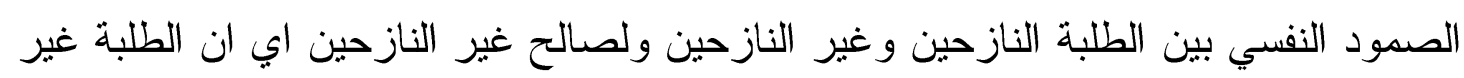

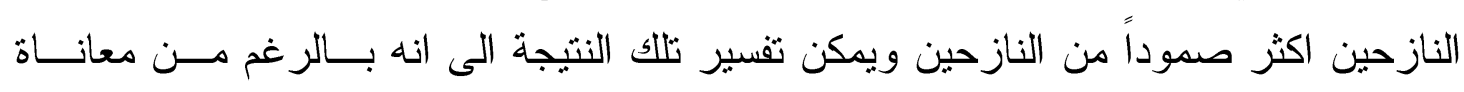

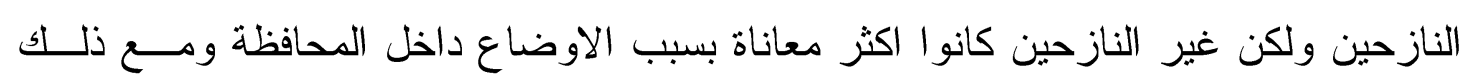
فانهم كانو ا صامدين نفسياً. 
مجل: الآراب / العدر ع ال|

جدول رقم (r)

نتائج الاختبار التائي لالالة

الفروق في الصمود النفسي

\begin{tabular}{|c|c|c|c|c|c|}
\hline \multirow{2}{*}{ الدلالة } & \multicolumn{2}{|c|}{ القيمة التائية } & \multirow{2}{*}{ الالمعياري } & \multirow{2}{*}{ المتوسط الحسابي } & \multirow[t]{2}{*}{ القيمة } \\
\hline & الجدولية & المحسوبة & & & \\
\hline \multirow{2}{*}{ دال } & 1.97 & $0 . M V$ & $10 . \leqslant \varepsilon$ & $1 \leqslant 9 . Y \wedge$ & النازحين غير V7 \\
\hline & & & A.ru & Irی.r & 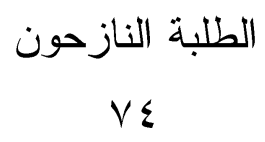 \\
\hline
\end{tabular}

وذلك بامتلاكهم الموارد او الذخيرة النفسية التي توجد لدى كل فرد منا وتوظف من قبل

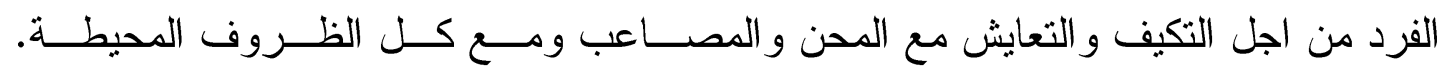

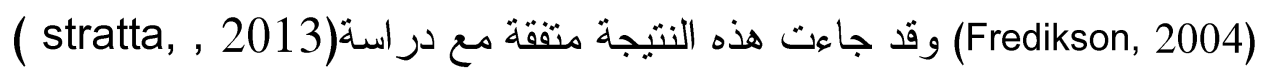

التوصيات: 1.اعداد البر امج الارشادية وتتفيذ المحاضر ات الاجتماعية و النفسية لعو ائل الطلاب النـازحين و غير النازحين في اهمبة الصمود النفسي وقت المحن و الصعاب.

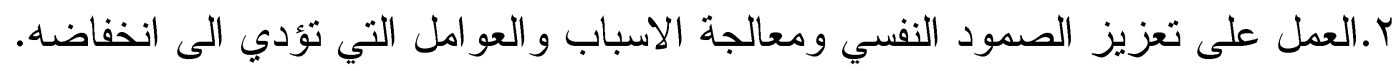

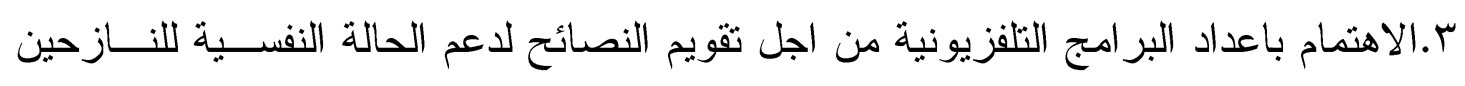

$$
\text { والمقترحات: }
$$

ا.بناء برنامج ارشادي لتتمية الصمود النفسي لدى طلبة المرحلة الثانوية.

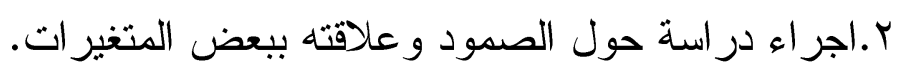
r.اجر اء در اسة مقارنة بالصمود ما بين ابناء الشهداء و اقر انهم. 


\section{المصادر العربية والاجنبية \\ اولا: المصادر العربية : الإنيان}

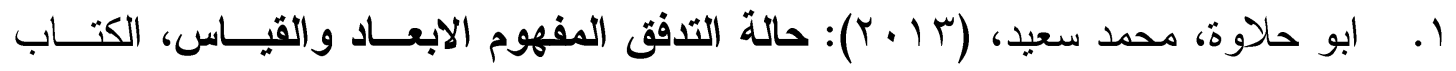

$$
\text { الالكتروني مكتبة العلوم النفسية العربية. }
$$

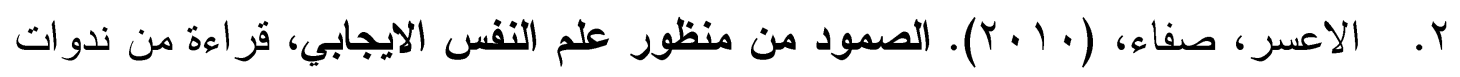

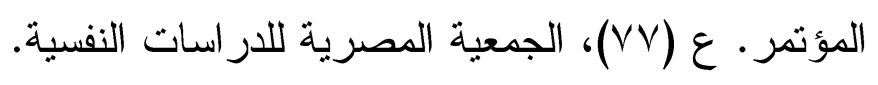

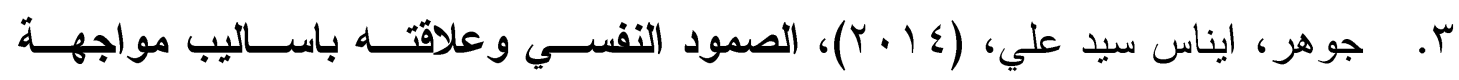

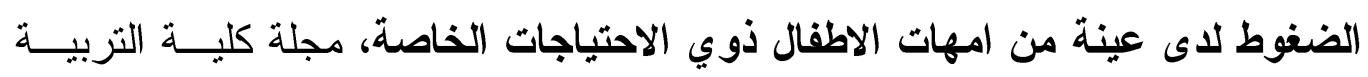

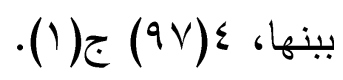

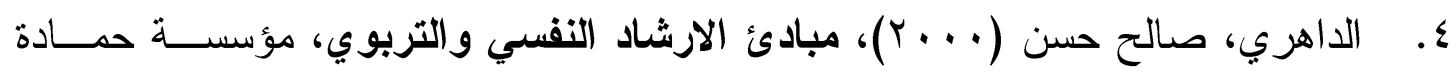

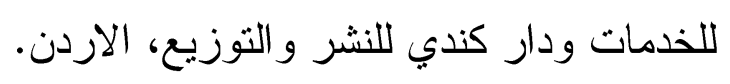

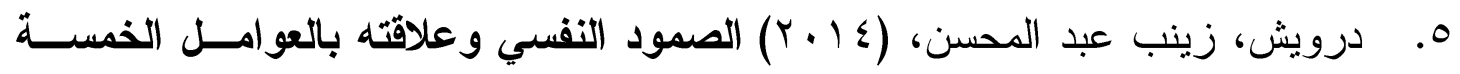

الكبرى للثخصية لاى عينة من الفتيات المتأخرات عن الزواج بمدينة الرياض، رسالة الكئة ماجستير ، جامعة نايف العربية للعلوم الامنية.

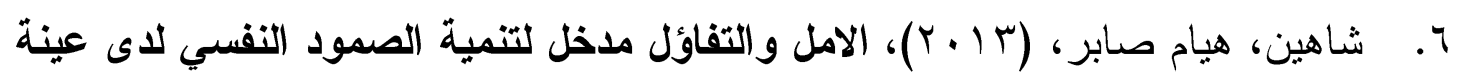

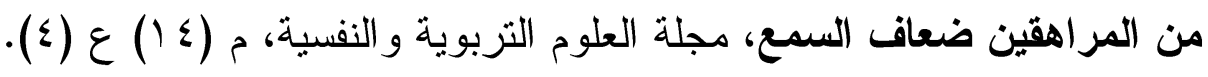

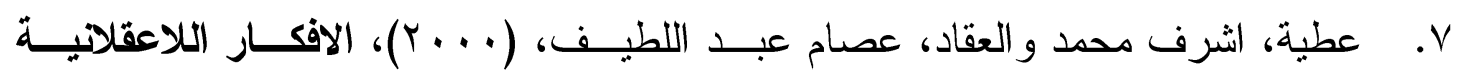

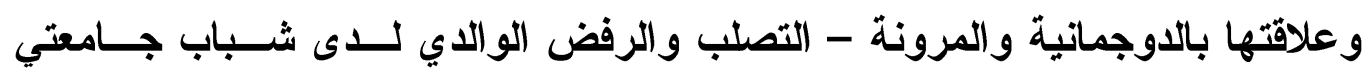

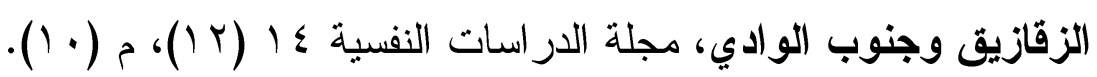

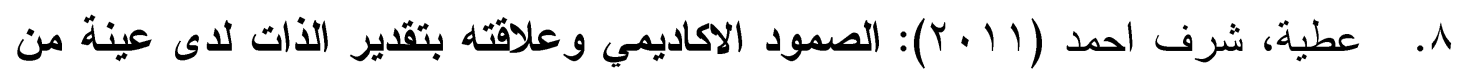

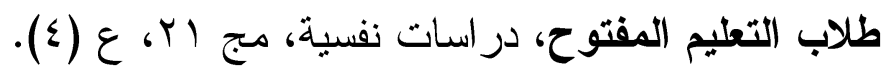




\section{ثانيا: المصادر الاجنبية}

9. Collins, A., (2010). Life experiences \& Resilience in college students: A relationship influenced by hope \& mindfulness. Unpublished Ph. D. Texas A \& M University, United states.

10. Dupleessis, Adrian, (2001). Resilience theory, A literature Review.

11. Flach. F. F. (2003). Resilience, Discovering anew strength at times of stress New York, WY. Heather light Press.

12. Koen, D., (2010). Resilience I Professional nurses. Thesis doctor for philosophy, in psychology and the vaal triangle campus of the North - West University.

13. Lee, H.H. \& Gran Ford (2008). Does Resilience moderate the associations between parental problem drinking and ad descents.

14. Leipold, B. \& Greve (2000), Resilience, A conceptual Bridge between coping and development psychologist.

15. Luthar, S.S \& Cicchettti, D., (2000). The construct of resilience: implications for interventions and social policies. Development and psychology. 12.

16. Machuca, R. (2010). Resilience characteristics of master s-level counseling students. (Doctoral dissertation). University of $\mathrm{New}$ Orleans, New Orleans.

17. Masten. A., \& Coatsworth. D. (1998). The development of competence in favorable and unfavorable environments. American Psychogist.

18. Riley, D., (2012). Work and family interface: Wellbeing and the role of resilience and work - life balance. Thesis doctor of philosophy in Waikato University.

19. Rose, A., (2009). Economic resilience to disasters. CARRI, research report 8 , final report to community and regional resilience institute. $\mathrm{P}: 1-40$. 
20. Rutter, M. (2007). Resilience, competence and coping, Child abuse and neglect, 31 (3).

21. Stratta, P: Capanna, C, Patrarca,S, Cataldo,(2013)Resilience in Adorle scenc gender differences two years er aft the earthquake of laquila personality and individual (54)

22. Trapp, C. (2010). The association among emotional intelligence resilience and academic performance of preserves teachers. (Doctoral dissertation). University of Phoenix.

23. Tusaie, K., Puskar, K. \& Sereika, S. (2007). A predictive \& moderating model of psychologist resilience in a adolescents. Journal of Nursing Scholarship.

24. Van, G. M., De puijter, M., \& Smeets, C. (2006). Citizens and resilience Amsterdam: Dutch Knowledge and Advise center.

25. Weaver, E. D. (2009). The relationship between cultural/ ethnic identity and individual protective factors of academic resilience. (Doctoral dissertation). The college of William and Mary in Virginia.

26. Wicks, C. R. (2005) Resilience: An integrative Frame work measurement, Loma Linda University.

27. William, H, David, Hhn, (2001). Usand well. Being in older widows, Adaptation and Resilience, Journal of women Aging, 23.

28. Windle, (2011). What is resilience? Are view and concept analysis Reviews in Clinical Gerontology, 21.

29. Yorgason, Jeremy., Piercy, F., \& Poercy, S. (2007). Acquired hearing impairment in older couple relationships: an exploration of couple resilience processes. Journal of aging studies, 21 (3). 
Psychological Resilience of University Students Displaced and non-displaced Dr.. Aseel Mohammed Sabbar

Dr. Lecturer

Anbar University / College of Education for Human Sciences / Department of Educational and Psychological Sciences Mumnmom@yahoo.com

\section{Abstract}

The goal of current research to identify significant differences in psychological resilience between university students displaced persons and their peers is displaced, and the research sample of ( 150 ) students(male and female), researcher prepared the scale, the search results are presence of statistically significant differences in favor of students is displaced . 